\title{
Motor potentials of bulbocavernosus muscle after transcranial and lumbar magnetic stimulation: comparative study with bulbocavernosus reflex and pudendal evoked potentials
}

\author{
A Ghezzi, L Callea, M Zaffaroni, R Montanini, G Tessera
}

\begin{abstract}
Motor potentials of the bulbocavernosus muscle were recorded in 17 healthy subjects after transcranial and lumbar magnetic stimulation. The latencies (SD) were respectively: $22.9(1.8)$ and 5.9 $(0.4) \mathrm{ms}$. The central conduction time was $17 \cdot 0(2 \cdot 5) \mathrm{ms}$. The bulbocavernosus reflex presented an onset at $34.5(3.3) \mathrm{ms}$ and a negative peak at $43.1(3.9)$ ms. The cortical pudendal evoked potential was W shaped: the first peak had a latency of $35.4(2.8) \mathrm{ms}$. The concurrent recording of motor potentials, bulbocavernosus reflex, pudendal evoked potentials gives a measure of peripheral and central, afferent and efferent neurological pathways related to pudendal nerve function.
\end{abstract}

From studies carried out by Merton and Morton ${ }^{1}$ and Barker et $a l,{ }^{2}$ it became possible to record motor potentials (MPs) of upper and lower limb muscles after cortical electrical or magnetic stimulation. An interesting development of these techniques seems to be the possibility of recording MPs of pelvic floor muscles when evaluating motor conduction from the cortex along the spinal cord: $:^{1-3}$ it should be particularly helpful in neurophysiological diagnosis of sphincter and sexual disturbances in addition to tests for evaluation of pudendal nerve function such as pudendal evoked potentials (PEPs) and bulbocavernosus reflex (BCR)..$^{47}$ Pudendal nerve is strictly involved with bladder, sexual and bowel function: it supplies the external urethral and external sphincters, pelvic floor and bulbocavernosus muscles. We attempted to record MPs of bulbocavernosus muscle to transcranial and lumbar magnetic stimulation, comparing results with PEPs and BCR.

Gallarate, Italy Multiple Sclerosis Study Centre A Ghezzi

L Callea

M Zaffaroni

Neurological

Department

R Montanini

Surgical Department G Tessera

Correspondence to: Dr Ghezzi, Centro Studi Sclerosi Multipla, Gallarate Hospital, Via Pastori 4, 20013 Gallarate, Italy

Received 14 May 1990 Accepted 20 September 1990 performed by a Novametrix Magstim mag-

Seventeen healthy male volunteers took part study. The mean age was 47.8 years (range 22-80), the mean height was $169.2 \mathrm{~cm}$ (range 161-188). All subjects were neurologically normal and had normal sphincric and sexual functions.

The bulbocavernosus muscle potential to magnetic stimulation was recorded using a surface $\mathrm{Ag} / \mathrm{AgCl}$ electrode referenced to $\mathrm{S} 1$,

\section{Material and methods}

netic stimulator, placing the coil over the vertex, or slightly anterior to it: in preliminary recordings this site was found optimal to obtain good responses. The intensity of stimulation was increased starting from $70 \%$ of the maximal output of the device. Lumbar stimulation was performed placing the coil over the L1 spinous process. Subjects were asked to relax and then to contract perineal muscles slightly: at least eight responses were recorded in the two conditions.

BCR-square wave stimuli of $0.1 \mathrm{~ms}$ duration were applied to the penis through ring electrodes. The intensity was increased gradually, above the sensory threshold but below the painful threshold. The frequency was $4 \mathrm{~Hz}, 10-100$ responses were averaged with a bandpass of 1-2000 Hz. (Recording electrodes as above).

PEPs-responses were recorded from the scalp (active electrode $2 \mathrm{~cm}$ behind $\mathrm{Cz}$, reference Fpz) and lumbar spine (L1-L5 electrodes). At least 250 responses were averaged, two recordings were obtained and superimposed. Filters: 1-2000 Hz. Stimuli characteristics were similar to those used for BCR recording.

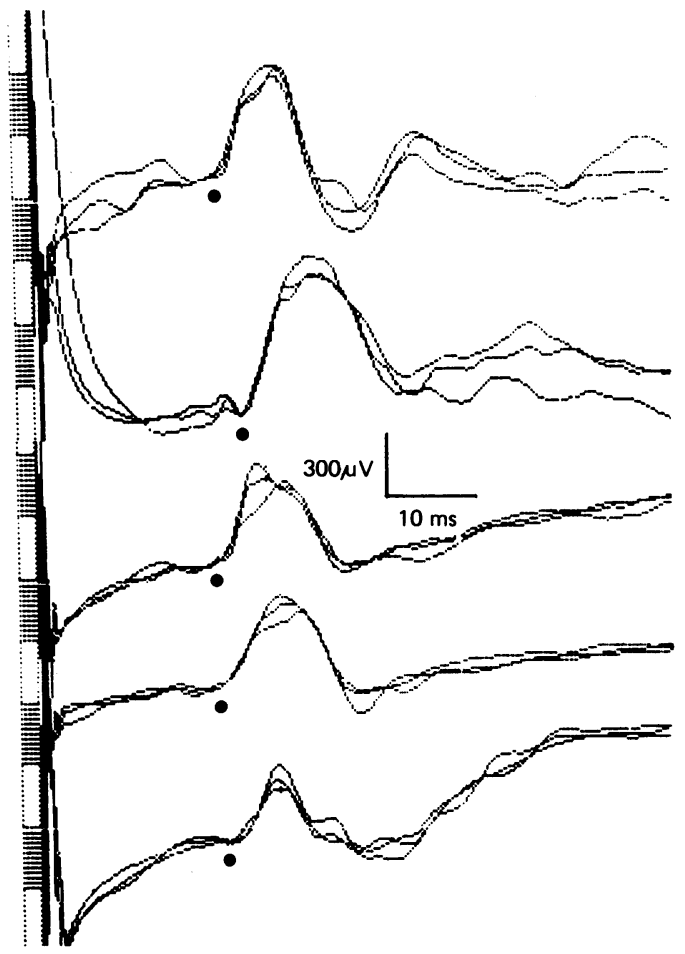

Figure 1 Examples of motor potentials from bulbocavernosus muscle following transcranial magnetic stimulation in five healthy subjects. 


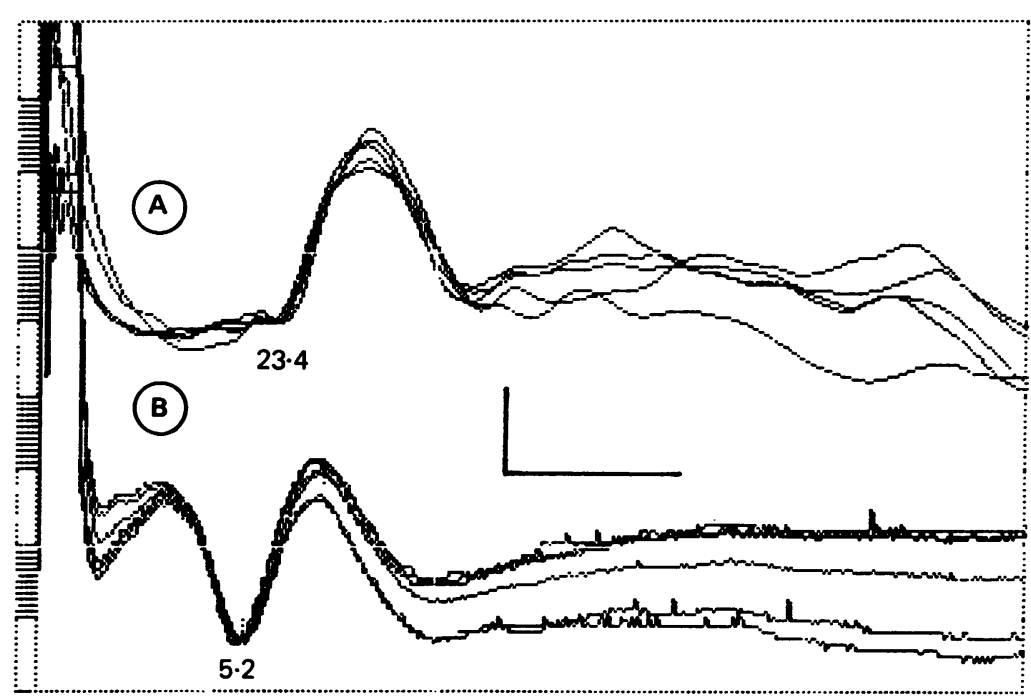

Figure 2 Motor responses after transcranial (a) and lumbar (b) stimulation. Calibration: $600 \mu \mathrm{V}$, time $20 \mathrm{~ms}(\mathrm{a})$ and $5 \mathrm{~ms}(\mathrm{~b})$.

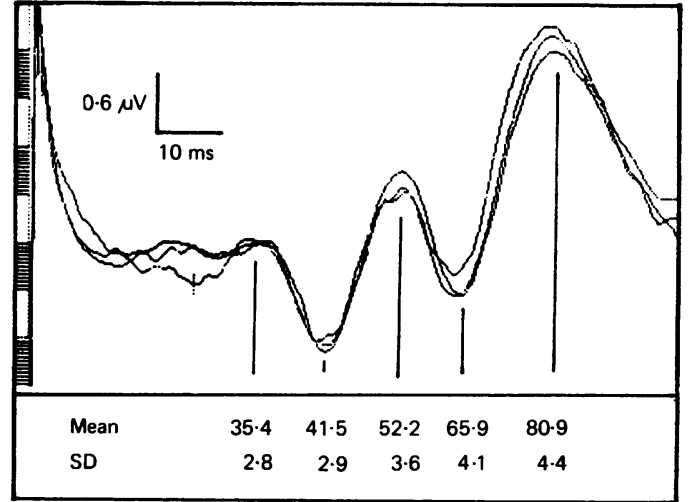

Figure 4 Example of cortical pudendal evoked potential. Mean (SD) normal values of the corresponding waves are reported $(\mathrm{ms})$.

\section{Discussion}

Our observations show that MPs of the bulbocavernosus muscle can be easily recorded with surface electrodes during mild pelvic muscle contraction. The latency of the response was $22.9(1.8) \mathrm{ms}$ in our series: a similar value was found by Merton and Morton in response to electric stimulation in some individual cases. ${ }^{13} \mathrm{We}$ are not aware of studies carried out with magnetic stimulation.

Placing the coil over the $\mathrm{L} 1$ spinous process an MP could be recorded with onset at 5.9 $(0.4) \mathrm{ms}$, a value similar to that obtained using electrical stimulation at the same spinal level. ${ }^{8}$ The motor CCT was $17.0(2.5) \mathrm{ms}$. In our laboratory the motor CCT is $11.5(1.7) \mathrm{ms}$ recording from the tibialis anterior muscle (unpublished data), in agreement with other reports. ${ }^{9-11}$ It means that conduction of motor fibres supplying pudendal motor neurons is slower than fibres supplying the spinal motor neurons in the legs.

The afferent and efferent conduction of pudendal nerve is evaluated by the BCR: the latencies of its onset and peak were respectively $34.5(3.3) \mathrm{ms}$ and $43.1(3.9) \mathrm{ms}$. The whole afferent pathway activated by electrical stimulation of the penis is measured by cortical PEPs: the response is characterised by an onset at $35.4(2.8) \mathrm{ms}$, followed by a positive peak at $41.5(2.9) \mathrm{ms}$. BCR and PEP latencies in our series are similar to the values of other studies. ${ }^{4-7}$

Lumbar PEPs were hardly recognisable in most cases of our series, making it hard to calculate the CCT of the afferent pathway. An indirect measure of peripheral sensory conduction can be given by the difference in lumbar MP latency from BCR: however, this value does not correspond to the afferent peripheral conduction (see below).

Haldeman et $a l^{4}$ found that the CCT after pudendal stimulation was $30.0(3 \cdot 2) \mathrm{ms}$. As the CCT of the afferent pathway in response to tibialis posterior nerve stimulation was 16.5 (1.6) $\mathrm{ms}$, they concluded that the central afferent pathway activated by pudendal nerve stimulation conducts more slowly than the one activated by the tibialis posterior nerve. This is similar to our finding with motor CCT. 
The latency of BCR is surprisingly higher than expected on the basis of latency of lumbar PEPs and MPs. As the lumbar PEP latency was approximately $12-13 \mathrm{~ms}$, Hadelman et $a l^{4}$ stated that the reflex should appear after 24-26 ms, assuming that the afferent and efferent limbs of the BCR conduct at the same velocities. This hypothesis is probably right: the latency of lumbar MPs (5.9 ms) was effectively lower than that proposed by Hadelman et $a l^{4}$ but spinal magnetic stimulation may activate the motor roots near to their exit from the spinal column. ${ }^{12}$ These findings are consistent with the fact that the BCR is a polysynaptic reflex.

The recording of RBC, PEPs and MPs to transcranial and lumbar magnetic stimulation permits evaluation of the peripheral and central afferent and efferent pathways concerned with sphincteric and genital functions: in clinical diagnosis they should help to evaluate the site of lesion in patients with bowel, urinary and sexual disorders of neurogenic aetiology.

1 Merton PA, Morton HB, Hill DK, Marsden CO. Scope of a technique fcr electrical stimulation of human brain, spinal cord, and muscle. Lancet 1982;ii:597-600.
2 Barker AT, Jalivous R, Freeston IL, Jarratt JA. Clinical evaluation of conduction time measurements in central motor pathways using magnetic stimulation of human brain. Lancet 1986;i:1325-6.

3 Merton PA. Electrical stimulation through the scalp of pyramidal tract fibers supplying pelvic floor muscles. In: Henry MM, Swash M, eds. Coloproctolory and the pelvic floor. Pathophysiology and management. London: Butterfloor. Pathophysiology
worths, 1985:125-8.

4 Haldeman S, Bradley WE, Bathia NN, Johnson BK. Pudendal evoked responses. Arch Neurol 1982;39:280-3.

5 Siroky MB, Sax DS, Crane RJ. Sacral signal tracing: the electrophysiology of the bulbocavernosus reflex. J Urol 1979;122:661-4.

6 Tackmann W, Porst H, Van Ahlen H. Bulbocavernosus reflex latencies and somatosensory evoked potentials after pudendal nerve stimulation in the diagnosis of impotence. J Neurol 1988;235:219-25.

7 Ertekin C, Akyurekli O, Gurses AN, Turgut $H$. The value of somatosensory-evoked potentials and the bulbocavernosus reflex in patients with impotence. Acta Neurol nosus reflex in patien
Scand 1985;71:48-53.

8 Snooks SJ, Swash M. Pudendal nerve terminal motor latency, and spinal stimulation. In: Henry MM, Swash M, latency, and spinal stimulation. In: Henry MM, Swash M, eds. Coloproctology and the pelvic floor. Pathophysiology

9 and management". London: Butterworths, 1985:112-24. conduction in multiple sclerosis: evaluation of abnormality revealed by transcutaneous magnetic stimulation of the brain. J Neurol Neurosurg Psychiatry 1987;50:159-66.

10 Hugon J, Lebeau M, Tabarand F, Chazot F, Vallet JM, Dumas $M$. Central motor conduction in motor neuron disease. Ann Neurol 1987;22:544-6.

11 Ugawa Y, Genda K, Shimpo T, Mannen T. Physiologic analysis of central motor pathways. Simultaneous recording from multiple relaxed muscles. Eur Neurol 1989; 29:135-40.

12 Ugawa Y, Rothwell JC, Day BL, Thompson PD, Marsden CD. Magnetic stimulation over the spinal enlargements. CD. Magnetic stimulation over the spinal enlargem
$J$ Neurol Neurosurg Psychiatry 1989;52:1025-32. 